\title{
Intonational encoding of double negation in Catalan
}

\section{Abstract}

In this paper we shall explore the phenomenon of double negation (DN) in a negative concord language like Catalan from an inferential perspective. According to recent developments within the generative approach to the theory of sentential grammar, a proper account of this phenomenon requires an analysis of the lexical, syntactic, and semantic conditions involved. Yet this model only attempts to account for the phenomenon of DN if two negative operators or two strong negative quantifiers are involved within a syntactic structure. In order to investigate the syntactic and prosodic conditions that affect DN interpretation in a question-answer (Q-A) dialogue in Catalan, we conducted a set of perception experiments with Central Catalan listeners. Our study supports the hypothesis that different formal conditions in the Q and A utterances (specifically, a command negative wh- Q combined with a contradictory intonational contour in the A) affect the corresponding interpretation, and that intonation encodes procedural restrictions on the proposition expressed. Results from these perception experiments confirm that the intonation contour of the negative word ningú 'nobody' is the key factor triggering a DN interpretation. This paper aims to contribute to our current knowledge of the prosody-meaning interface in the interpretation of negative constructions within recent work on the intonational phonology of Catalan and Relevance Theory.

Keywords: double negation, intonation, procedural meaning, Catalan. 


\section{Introduction}

The point of departure for this research is the observation that a negative indefinite expression (henceforth $n$-word, following Laka's 1990 terminology) used as a fragment answer in Catalan dialogues like that seen in (1) can convey two distinct interpretations: a single negation (1a), as expected from the negative property it is supposed to encode (see Espinal, 2000), and a double negation (1b), yielding a positive reading 'everybody' which is not expected to be inferred given the lexical semantics of the n-word. ${ }^{1}$ Note that all negative items appear in italics, while capital letters indicate focus on the wh- word and marked intonation on the n-word.

$\begin{array}{llll}\text { (1)a. Qui no ha menjat postres? } & \text { Ningú. } & \text { (Single Negation) } \\ \text { who not has eaten dessert } & \text { nobody } & \\ \text { 'Who did not eat dessert?' } & \text { 'Nobody.' [= Nobody ate dessert.] } \\ \text { b. QUI no ha menjat postres? } & \text { NINGÚ. } & \text { (Double Negation) } \\ \text { who not has eaten dessert } & \text { nobody }\end{array}$

'Who didn't eat dessert?' 'Nobody.' [= Nobody did not eat dessert: everybody did eat dessert.]

The general goal of this paper is to explore the phenomenon of double negation (DN) in a (nonstrict) negative concord (NC) language like Catalan from an inferential perspective and a contextually-based approach. Our aim is to find out the syntactic and prosodic conditions that trigger a single negation or a DN interpretation in question-answer (Q-A) dialogues and therefore help to disambiguate cases like those in (1).

We will argue for two hypotheses, a general one $\mathrm{H} 1$ and a more specific one $\mathrm{H} 2$, which aim to show the important role that intonation plays in utterance interpretation, and the sort of interaction that is dynamically activated between intonation and procedural meaning.

H1 Different tonal events in Q-A pairs affect the corresponding interpretation. 
H2 Intonation encodes procedural restrictions not only on higher-level explicatures but also on the communicated proposition or explicature. That is, prosodic tunes constrain the proposition expressed. $^{2}$

Let us start with a description of the phenomenon of DN and its possibilities in a NC language.

\subsection{DN in a NC language}

DN is a phenomenon of multiple negation whereby two negative elements cancel each other out. Consider the data in (2), where SE stands for Standard English, F for French, and C for Catalan. (2a-b) illustrate the phenomenon of DN within a single clause, whereas (2c) introduces the phenomenon in a more complex structure with a main clause and a subordinate clause.

(2) a. SE I don't want to do nothing. (= I don't want to just do nothing: I want to do something.)

b. F Il n' est pas venu pour rien. (Hendriks et al., 2009)

he ne is not come for nothing

'He didn't come for nothing.'

c. C No crec que no vingui.

not believe that not come

'I don't think that (s)he is not going to come.'

This phenomenon is usually contrasted with the process of NC, whereby two or more negative elements yield one negation in the semantics. See (3), where NSE stands for Non-Standard English, R for Romanian, and S for Spanish.

(3) a. NSE I'm not doing nothing for you. $\quad$ (Tubau, 2008)

b. R Nimeni $*(n u)$ a venit. (Falaus, 2007)

nobody not has come 
'Nobody came.'

c. S Nadie $\left({ }^{*}\right.$ no) hará nunca nada por ti.

nobody not do.FUT never nothing for you

'Nobody will ever do anything for you.'

Giannakidou (2000) further distinguishes two types of NC languages: Strict NC and Non-strict NC languages (Romanian versus Spanish, for example). In Strict NC languages every negative indefinite must be accompanied by a negative marker, whereas in Non-strict NC languages the negative marker is required for postverbal n-words but may or may not occur in clauses containing preverbal n-words (e.g., in Catalan the negative marker is optional, but in Spanish and Italian it is ruled out, as illustrated in (3c)).

This distinction is interesting because it has been correlated with the phenomenon of DN mentioned above. It has been generally accepted that in Strict NC languages DN is never allowed (Giannakidou, 2002). However, Falaus (2007) has pointed out that Romanian, despite being a Strict NC language, still allows a DN interpretation when two or more n-words co-occur, as illustrated in (4).

(4) Nimeni nu iubeste pe nimeni.

$(\mathrm{NC} / \mathrm{DN})$

nobody not loves DOM nobody

'Nobody loves anyone / Everybody loves someone.'

This instance of DN in Romanian corresponds to a marked interpretation which tends to be rare in spontaneous speech (Horn, 1989; Zeijlstra, 2004), yet it is nonetheless a possible interpretation under specific contextual environments. It is a marked reading because it implies the denial of an accessible negative proposition, either a piece of information explicit in the preceding discourse, an inference warranted by preceding text, or a piece of information stored in the common ground (cf. Dryer, 1996; Prince, 1992). ${ }^{3}$ A marked meaning (e.g., a DN, rather than a single negation 
reading), like a non-canonical meaning (e.g., 'emphatic', 'presuppositional' or informationstructurally-based meaning), is presumed to pair with either a marked form (e.g., two negative operators or two negative quantifiers within a clause) or a non-canonical form (e.g., a negative expression combined with pas in Catalan and French, tampoco in Spanish, or mica in Italian; Espinal, 1993; Schwenter, 2003; Mosegaard Hansen \& Visconti, 2009). However, in (1b) above it is apparently the same syntactic form that encodes either a single negation or a DN interpretation. Therefore, we need to find out what constrains the difference in interpretation. ${ }^{4}$

With this in mind, let us briefly consider how and to what extent the phenomenon of DN can be accounted for within the theory of grammar. Recent accounts within the generative grammar tradition (see Haegeman, 1995; Giannakidou, 2001; Zeijlstra, 2004; Espinal, 2000, 2007; Tubau, 2008; and others) have focused on various factors that have proved to be crucial for choosing between a DN or a NC interpretation for an expression that contains negative expressions, namely: (i) the properties of the various lexical items that encode a negative meaning (either a negative operator, an n-word, a negative quantifier, or a polarity item); ${ }^{5}$ (ii) the set of syntactic conditions that regulate the distribution of negative items (i.e., checking requirements, presence of abstract negative operators, deletion of overt negative operators under ellipsis, number of negative operators per clause, etc.); and (iii) the set of possible post-syntactic operations that determine the overt morphophonological properties of these items (i.e., an operation of obliteration that eliminates the negative marker syntactic terminal from the morphological structure, and an operation of impoverishment that inserts for a language like English a default form of the any-set; see Tubau, 2008). Finally, from a formal semantics perspective two different modes of composition have been postulated at the level of logical representation in order to account for the two interpretations we encounter (i.e., an operation of 
iteration of monadic negative quantifiers in the case of $\mathrm{DN}$, and an operation of resumption into a polyadic quantifier in the case of NC; see de Swart \& Sag, 2002).

All this theoretical machinery is intended to find an explanation for the set of different (lexical, syntactic, post-syntactic, and semantic) conditions that must hold in order to trigger the application of the Law of DN as expressed in (5)

$$
\neg \neg \mathrm{p} \leftrightarrow \mathrm{p}
$$

Yet note that this model can only account for the phenomenon of DN if either two negative operators or two negative quantifiers are involved within a linguistic structure. Special machinery would be additionally required in order to account for the variation we find within the $\mathrm{NC}$ paradigm, for example, among Romance languages. Consider the data in (6), which shows that Italian and French behave differently from Catalan with regard to the semantic interpretation of a construction that combines a preverbal focalized n-word and a negative operator. ${ }^{6}$

(6) a. I NESSUNO non viene. $\quad$ (DN) (Corblin \& Tovena, 2003: ex. (82)) nobody not come 'Everybody is coming.'
b. F RIEN ne va pas.
(DN)
(Corblin \& Tovena, 2003: ex. (83)) nothing NEG works not 'Everything works.'
c. C
A NINGÚ (no) ha vist! (NC)
(Espinal, 2007)
to nobody not has seen
'(S)he saw nobody!'

In Catalan the most common syntactic environment that licenses DN is the one exemplified in (2c) (No crec que no vingui lit. not believe that not come 'I don't think that (s)he is not going to 
come'), characterized by the presence of a negative operator in the main clause and a second negative operator in the subordinate clause. We can also find DN readings within a single sentential structure (i) in restructuring constructions which present more than one negative marker within a complex VP (e.g., No vull no fer res lit. not want not do anything 'I don't want to do nothing'), and (ii) in sentences that contain a negative morpheme, a negative preposition or a negative verb under the scope of a negative operator (e.g., No estudia sense protestar lit. not studies without protesting '(S)he can't study without complaining'; see Espinal, 2002:2775). All this notwithstanding, in Catalan a reading of $\mathrm{DN}$ can also be inferred from n-words that occur isolated in Q-A pairs, as was already illustrated in (1b) (QUI no ha menjat postres? NINGÚ lit. who not has eaten dessert nobody 'Who did not eat dessert? Nobody' [=Nobody did not eat dessert: everybody did eat dessert]). In the rest of the paper our goal is to identify the formal and conversational conditions that make this reading possible.

\subsection{DN in Q-A pairs}

The fact that an isolated n-word uttered as an A to a negative wh- Q might convey a DN interpretation has been mentioned in the literature on Romance languages (for French, Italian, and Romanian, see Corblin, 1994, 1995; Corblin \& Tovena, 2003; and Falaus, 2006, 2007), starting with Corblin's observation for French. Consider the data in (7).

(7) a. F Qui n' a rien fait? Personne. (DN) (Corblin, 1994, 1995: ex. (81))

who NEG has nothing done nobody

'Who did not do anything?' 'Nobody.' [= Everybody did something.]

b. I Cosa non hai visto ? Niente. (DN) (Corblin \& Tovena, 2003: ex. (92b))

what not have seen nothing

'What did you not see?' 'Nothing.' [= I saw everything.] 
c. R Cine nu a mâncat nimic? Nimeni. (DN) (Falaus, 2006: ex. (24)) who not has eaten nothing nobody

'Who did not eat anything?' 'Nobody.' [= Everybody ate something.]

The question that arises immediately is how we can account for these phenomena, given that the n-words that appear as fragment answers in (1b) ('Nobody [did not eat dessert]') and (7) might be assumed to encode, by default, a negative meaning, as was properly exemplified in (1a) ('Nobody [ate dessert]').

Under a strong syntax-prosody approach, it must be postulated that isolated n-words can occur in different syntactic structures, and from these positions they are able to constrain different meanings: either a single negation interpretation or a DN reading. One such approach could be based on Rizzi's $(1997,2001)$ hypothesis for a complex system of functional heads at the left periphery (see (8)). Following this analysis an isolated n-word (e.g., the two answers in (1), repeated in (9)) could in principle be associated with either [Spec,Fin], [Spec,Topic], or even [Spec,Focus], and show a structural ambiguity.

(8) [ ForceP TopP* FocP TopP* FinP IP ]

(9)a. Qui no ha menjat postres? Ningú. (Single Negation) who not has eaten dessert nobody

'Who did not eat dessert?' 'Nobody.' [= Nobody ate dessert.]

b. QUI no ha menjat postres? NINGÚ. (Double Negation)

who not has eaten dessert nobody

'Who didn't eat dessert?' 'Nobody.' [= Nobody did not eat dessert: everybody did eat dessert.]

Unfortunately, there is no evidence for claiming that an isolated n-word must necessarily occur in one particular Specifier position. ${ }^{7}$ On the other hand, under such a syntactic analysis the two 
different interpretations (single negation or DN) could not be easily accounted for unless additional assumptions about the varying quantificational status of n-words were also made, and unless a null negative operator was postulated at a syntactic projection different from the one the n-word specifies. These two requirements would constrain syntactically the application of the Law of DN. Therefore, the problem of extending a syntactic analysis of the left periphery to the data studied here is that it becomes necessary to postulate (i) that isolated n-words can occur at various peripheral positions, even though there might not be any positive syntactic evidence for this assumption, and that (ii) at a functional projection different from the one occupied by the nword there occurs a non-overt negative head, for which there is no clear syntactic evidence either. Therefore, we conclude, along with Kaiser (2006:347), that the mapping between syntax and pragmatics must be rather underspecified.

Corblin $(1994,1995)$ approaches the syntax-prosody interface from a different non-hardwired syntactic perspective, by focusing on stress and prosodic phrasing. In particular, he claims that the $\mathrm{A}$ to the $\mathrm{Q}$ in the French example in (7a), repeated in $(10 \mathrm{a})$, can only have a DN interpretation, and relates this phenomenon to the interpretation of (10b), with strong stress on the first negative quantifier.

(10)a. Qui n' a rien fait? Personne.

(DN) (Corblin, 1994, 1995: ex. (81))

who NEG has nothing done nobody

'Who did not do anything?' 'Nobody.' [= Everybody did something.]

b. PERSONNE // n' a rien fait.

$(\mathrm{DN})$

nobody NEG has nothing done

'Nobody did nothing.' [= Everybody did something.]

Corblin's account is based on the assumption that stress triggers a focus-topic partition, and that this as well as the Q-A association divide the utterance in two parts at the time of processing. "If 
this is so, in each part there is one negative to process, and as a consequence, the representation of the whole construction will have one negation per negative, hence cannot be mono-negative" (Corblin, 1995:34). Therefore, one negation cancels the other, and the inferred interpretation is DN.

Inspired by Corblin's work, in this paper we set out to investigate the role prosody plays in constraining meaning, and the syntactic and prosodic conditions that connect Q-A dialogues with a DN or a single negation interpretation in Catalan. This research (as will be presented in Sections 2 and 3) shows that it is not stress or prosodic phrasing that constrains the final interpretation associated with an isolated n-word, but intonation. Our research supports the hypothesis that prosodic tunes are the deciding factor for DN interpretation in these Catalan constructions. Thus, our study supports Fretheim's (1996, 1998, 2002), House's (1996), and Escandell's (1998) hypothesis on the role of intonation in inferential processing.

\section{Methodology}

\subsection{Hypotheses}

As stated in the Introduction, n-words like ningú 'nobody' in Catalan used as fragment answers can be interpreted as a single negation (1a) or as a double negation (1b). Our initial hypothesis is that a set of syntactic and prosodic factors help to trigger a DN interpretation in this language. With respect to the prosodic cues, the examples in $(1 \mathrm{a}, \mathrm{b})$ illustrate the schematic intonation patterns found in these Q-A pairs. The single negation interpretation in (11a) is instantiated through the use of an information-seeking (e.g., neutral) wh- question intonation followed by a broad focus statement intonation in the A. By contrast, the DN interpretation in (11b) is realized through the use of an imperative wh- question intonation (with a focalized wh- word), followed 
by a contradictory intonation contour in the A. ${ }^{8}$ See the paragraphs below and Prieto (2002, in press), and Prieto et al. (2009) for a description of these intonation contours.

(11) a.

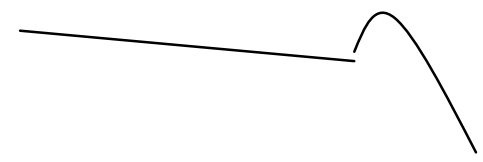

Qui no ha menjat postres? 'Who did not eat dessert?'

b.

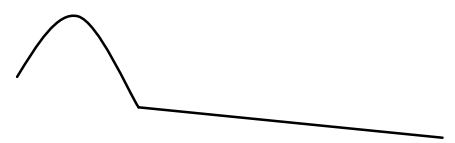

QUI no ha menjat postres? 'Who didn't eat dessert?'

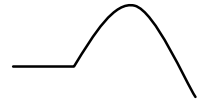

Ningú (Single Negation)

'Nobody' (= Nobody ate dessert.)

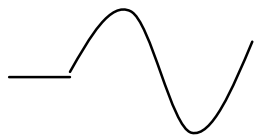

NINGÚ (DN)

'Nobody' (= Nobody did not eat dessert: everybody did eat dessert.)

For analyzing the Catalan intonation contours, we assume the Autosegmental-Metrical (AM) model (Pierrehumbert, 1980; Pierrehumbert \& Beckman, 1988; Ladd, 1996; and others), and specifically the Cat_ToBI system of prosodic annotation of Catalan corpora (Aguilar et al., 2009; Prieto et al., 2009; Prieto, in press). ${ }^{9}$ In this model, intonational tunes consist of strings of one or more pitch accents (or pitch movements associated with metrically strong positions) plus boundary tones (or pitch movements associated with the edges of prosodic constituents).

The two graphs in Figure 1 show the waveform display, spectrogram, f0 contour, and orthographic and tonal transcriptions of the Q-A pair Qui no ha menjat postres? Ningú 'Who did not eat dessert?' 'Nobody' with a single negation reading (upper graph) and a DN reading (bottom graph), as produced by a Central Catalan speaker. The intonation of the informationseeking wh- question has the intonational focus on the last word of the utterance postres 'dessert', which receives a high pitch accent (it is the highest pitch accent in the utterance, see 
Figure 1 below), and it is represented with an $\mathrm{H}^{*}$ in the Cat_ToBI system. By contrast, two prosodic features characterize the wh- question in DN readings, namely the presence of the high focal pitch accent on the wh- word qui 'who' (which receives the highest pitch accent, transcribed as $\mathrm{H}^{*}$ ), and the presence of a boundary tone L- immediately following this pitch accent. Thereafter, the rest of the sentence is totally deaccented and has a flat pitch.

The intonation of the n-word also differs greatly in the two interpretations. On the one hand, the n-word ningú 'nobody' with a negative interpretation has the typical broad focus statement intonation. It is produced with a $\mathrm{L}+\mathrm{H}^{*} \mathrm{~L} \%$ intonational contour (that is, a rise in the accented syllable followed by a low tone at the end of the utterance). On the other hand, the nword with a double negation interpretation is produced with what we will call the "contradictory contour', namely a rising pitch accent $\mathrm{L}+\mathrm{H}^{*}$ associated with the accented syllable followed by a complex boundary tonal movement LM\% (e.g., a fall-rise pitch movement at the end).

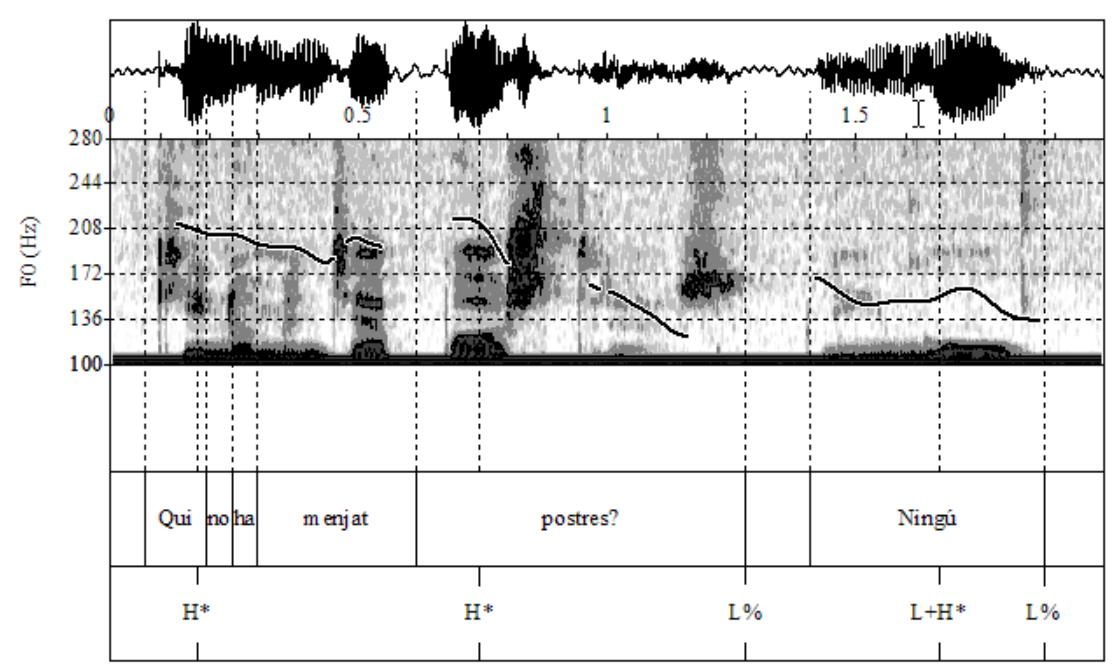




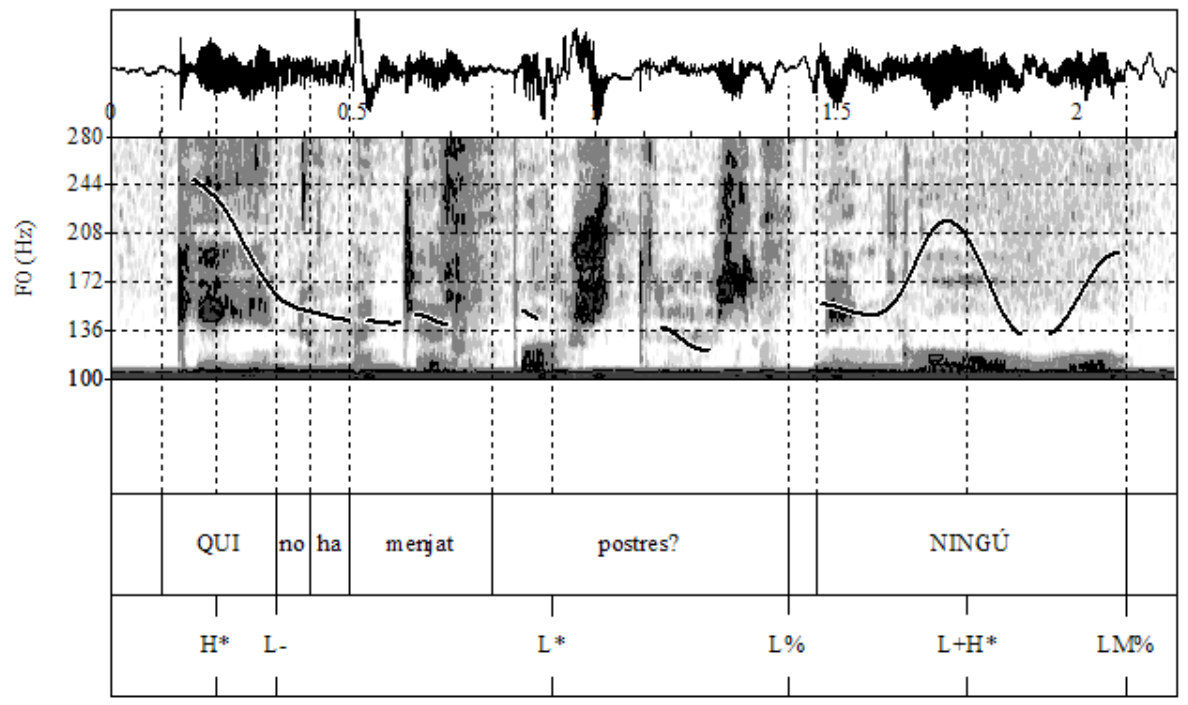


Figure 1: Waveform displays, spectrograms, f0 contours, and orthographic transcription of the Q-A pair Qui no ha menjat postres? Ningú 'Who did not eat dessert?' 'Nobody' with a single negation reading (upper graph) and a DN reading (bottom graph), as produced by a Central Catalan speaker.

The contradictory tune is a specific intonation contour in Catalan which on the one hand constrains information on the attitude of the speaker (to be inferred by the listener): the speaker is assumed to be sure about a specific piece of information (it is a 'statement of the obvious' contour; Aguilar et al., 2009; Prieto, in press), and the listener is assumed to share this strong conviction. On the other hand, in the specific case of the Q-A pair with a DN reading illustrated in (1b) (see Figure 1, right graph), the speaker also uses this contour with a counterexpectational meaning, expressing a denial of a discourseactivated assumption (namely, that someone has not eaten dessert).

Similar contrasts lead us to hypothesize that a set of prosodic and syntactic restrictions favour a $\mathrm{DN}$ reading of the $\mathrm{A}$ in Catalan, namely: (a) the presence of a focalized wh- word in the Q, (b) the presence of an additional n-word in the Q, and (c) the presence of a contradictory intonation contour on the n-word. With the goal of testing this hypothesis and investigating the role played by each one of these factors in the interpretation of $\mathrm{DN}$ by Catalan listeners, we conducted the two perception experiments described below.

\subsection{Experiment 1}

Experiment 1 dealt exclusively with the interpretation of the target n-word ningú 'nobody'. This n-word can occur in argument position, either in subject or object position. In the examples that follow ningú is associated with a subject functional 
category. An identification task was designed so that we could test the potential effects of the prosodic and syntactic conditions described above on a DN interpretation. In the identification task subjects were asked to respond after each stimulus by indicating whether they interpreted the n-word as conveying either a single or a double negation.

The materials used for Experiment 1 were the six short dialogues shown in (13), produced after hearing one of the contextual settings in (12). With regard to the two discourse contexts, (12a) was used for non-focalized wh- questions and (12b) for focalized wh- questions. Note that these discourse contexts were designed to activate the assumption made by the mother that someone did not eat dessert. However, even though both (12a) and (12b) activate this assumption, only (12b) states explicitly that the mother is upset with the thought that she is entertaining.

(12) Contextual Settings

a. Una mare és a la cuina i creu que algú dels convidats no ha menjat postres. Els pregunta si hi ha algú que no ha menjat postres.

'A mother is in the kitchen and suspects that some of her guests did not eat dessert. She asks if anyone did not eat dessert.'

b. Una mare entra al menjador, veu que hi ha la fruitera plena i demana enfadada si hi ha algú que no s'ha menjat les postres.

'A mother enters the dining room, sees that the fruit bowl is full and asks angrily if there is anyone who did not eat dessert.'

(13) Target utterances for Experiment 1. ${ }^{1011}$

CODES TARGET UTTERANCES

NEG 1 - Qui no ha menjat postres? -Ningú.

who not has eaten dessert nobody

'Who did not eat dessert?' 'Nobody.' 
NEG 2

—Qui és que no ha menjat res?

—Ningú.

who is that not has eaten nothing

nobody

'Who did not eat anything?'

'Nobody.'

DN1-ALL

-QUI no ha menjat postres?

—NINGÚ.

WHO not has eaten dessert

nobody

'Who did not eat dessert?'

'Nobody.'

DN2-ALL

—QUI no ha menjat res?

—NINGÚ.

WHO not has eaten nothing

nobody

'Who did not eat anything?'

'Nobody.'

DN3-ALL

—Qui és que no ha menjat postres?

—NINGÚ.

who is that not has eaten dessert

nobody

'Who did not eat dessert?'

'Nobody.'

DN4-ALL

—Qui és que no ha menjat res?

—NINGÚ.

who is that not has eaten nothing

nobody

'Who did not eat anything?'

'Nobody.'

The variables in this experiment were the [+/- focus] on the wh- word in the Q, the presence/absence of an extra n-word like res 'nothing' in the Q, and the intonation of the n-word in the A. ${ }^{12}$ While some of the Q-A pairs, coded as NEG, reflected the target prosodic characteristics of single negation (that is, [-focus] on the wh- word and a statement intonation on ningú; see Figure 1, left graph), other Q-A pairs reflected the typical prosodic cues for DN interpretation (that is, [+focus] on the wh- word and presence of a contradictory contour on ningú; see Figure 1, right graph). Note that in the target utterances in (13) the words in capitals indicate on the one hand [+focus] on the wh- word and on the other hand the presence of a contradictory contour on the n-word. 
Moreover, some of the target utterances contain an extra n-word: res 'nothing' in the question.

Nineteen native speakers of Central Catalan aged between 23 and 55 participated in this experiment. Subjects were seated in front of a laptop in a quiet room and the stimuli were played back through headphones. The perception test was played by means of E-Prime and lasted a total of approximately 30 minutes. Subjects had to listen to the target minidialogues in (13), which appeared after one of the two discourse contexts in (12), and had to decide whether the interpretation of the n-word was negative (meaning 'nobody') or positive (meaning 'everybody'), corresponding respectively to a single or double negation reading. Subjects had to press the "N" key of ningú 'nobody' for the single negation interpretation, and the "T" key of tothom 'everybody' (i.e., the Catalan positive universal quantifier) for the DN interpretation (see the gloss of (1b); Nobody did not eat dessert: everybody did eat dessert). One training block was included before the test session. The experiment contained 7 repetitions of each trial. The total number of responses analyzed was 798 (19 listeners x 6 conditions x 7 repetitions).

\subsection{Experiment 2}

Experiment 2 was also an identification task. In this case we dealt with two argumental n-words: ningú 'nobody', which in the experiment was associated with a subject functional category, and res 'nothing', which was associated with an object functional category. ${ }^{13}$ It was a follow-up of Experiment 1 that had the goal of testing separately the potential effects of the presence of focus in the wh- word and the intonation of the nword in DN interpretation. In this identification task, subjects were asked to respond after each stimulus by indicating whether they interpreted the n-word as a single negation or a double negation. 
The target materials of Experiment 2 corresponding to the n-word ningú 'nobody' were the twelve short dialogues in (15), which followed one or the other of the two contextual settings provided in (14). In contrast to (12), note that these contexts omit any lexical item that codifies conceptual information on the attitude of the speaker at the time of expressing the utterance (e.g., enfadada 'angry' in (12b)). This is because we wanted to test the reliability of our second hypothesis, in particular, the role of intonation at the time of constraining information on the attitude of the speaker and at the time of constraining information on the proposition expressed. Importantly, this time the manipulated variables in the experimental dialogues was the presence/absence of a focused wh- word in the Q and the target intonation in the response.

(14) Contextual Settings

a. Una mare entra al menjador quan els altres tres membres de la família estan entaulats. Mira la fruitera i demana...

'A mother enters the dining room while the three other members of the family are eating. She looks at the fruit bowl and asks...'

b. Una mare entra al menjador quan els altres tres membres de la família estan entaulats. Mira els plats i demana...

'A mother enters the dining room while the three other members of the family are eating. She looks at their plates and asks:'

(15) Target utterances for Experiment 2 - ningú. ${ }^{14}$

CODES

TARGET UTTERANCES

NEG1

- Qui no ha menjat postres?

-Ningú.

who not has eaten dessert

nobody

'Who did not eat dessert?'

'Nobody.'

NEG2

-Qui no ha menjat res?

—Ningú. 
who not has eaten nothing

'Who did not eat anything?'

NEG3

NEG 4

DN1-ALL

DN1-FOC

DN1-INT

DN2-ALL

DN2-FOC

DN2-INT
-Qui és que no ha menjat postres?

who is that not has eaten dessert

'Who did not eat dessert?'

- Qui és que no ha menjat res?

who is that not has eaten nothing

'Who did not eat anything?'

— QUI no ha menjat postres?

WHO not has eaten dessert

'Who did not eat dessert?'

— QUI no ha menjat postres?

WHO not has eaten dessert

'Who did not eat dessert?'

— Qui no ha menjat postres?

WHO not has eaten dessert

'Who did not eat dessert?'

— QUI no ha menjat res?

WHO not has eaten nothing

'Who did not eat anything?'

— QUI no ha menjat res?

WHO not has eaten nothing

'Who did not eat anything?'

— Qui no ha menjat res?

WHO not has eaten nothing nobody

'Nobody.'

- Ningú.

nobody

'Nobody.'

- Ningú.

nobody

'Nobody.'

—NINGÚ.

nobody

'Nobody.'

- Ningú.

nobody

'Nobody.'

- NINGÚ.

nobody

'Nobody.'

—NINGÚ.

nobody

'Nobody.'

— Ningú.

nobody

'Nobody.'

- NINGÚ.

nobody 
'Who did not eat anything?'

'Nobody.'

DN3-ALL

—Qui és que no ha menjat postres?

—NINGÚ.

who is that not has eaten dessert

nobody

'Who did not eat dessert?'

'Nobody.'

DN4-ALL

- Qui és que no ha menjat res?

-NINGÚ.

who is that not has eaten nothing

nobody

'Who did not eat anything?'

'Nobody.'

Crucially, as already mentioned, these materials combined the two factors that we wanted to control separately: namely, the [+focus] on the wh- word and the intonation of the response. We also tested the effects of the presence of an additional n-word in the wh- question. Those Q-A pairs coded as NEG share an A with a statement intonation. NEG3 and NEG4 differ from NEG1 and NEG2 in that the wh- expression is syntactically focused. Q-A pairs coded as DN test focus (phonological or syntactic) on the wh- expression relative to the weight of a marked intonation contour (i.e., a contradictory tune) on the n-word in the A. Note that (i) the words in capitals indicate [+focus] on the wh- word and the presence of a contradictory contour on the n-word, (ii) those Q-A pairs coded as FOC contain a [+focus] feature on the wh- word and a noncontradictory (i.e., statement) intonation in the response, (iii) those Q-A pairs coded as INT contain a contradictory contour in the response and no focus on the wh- word, and (iv) those Q-A pairs coded as DN-ALL contain both a focused wh- expression and a contradictory contour in the A.

The materials used in this experiment were replicated with 12 similar minidialogues focusing on the interpretation of res 'nothing', with the same conditions applied. (See Appendix 1 for this version of the materials.) 
Twenty-four Central Catalan listeners participated in the experiment. The procedure to collect the listener's responses was the same as in Experiment 1. Subjects had to listen to the target dialogues, which appeared after a discourse context, and had to decide whether their interpretation of the n-word was negative or positive. In this case, they had to press the " 0 " key for the single negation interpretation ('nobody'/"nothing') and the "3" key for the DN interpretation ('everybody'/'everything'). These keyboard keys were used because, in accordance with the contextual setting which was made available to the listeners, for each target utterance, the interpretation of the n-word corresponded to either three (all) or zero (none) individual entities or objects.

The experiment lasted a total of 60 minutes. One training block was included before the test session. The experiment contained 4 repetitions of each trial. The total number of responses analyzed was 2,304 (24 listeners x 12 conditions x 4 repetitions $\mathrm{x}$ 2 target n-words).

\section{Results}

\subsection{Results of Experiment 1}

Figure 1 shows the mean identification rate for the interpretation of ningú 'nobody' ("1" $=$ everybody; " 0 "=nobody) as a function of the six prosodic and syntactic conditions set up for Experiment 1, for all listeners. The results in the graph clearly show that the responses are distributed in two separate groups. On the one hand, the Q-A pairs which contained a focus feature on the wh- word together with the contradictory tune on the nword (DN1-ALL, DN2-ALL, DN3-ALL, DN4-ALL) triggered a positive interpretation of the n-word. The group mean identification rate was 0.68 . On the other hand, the Q-A 
pairs pronounced with the unmarked wh- question intonation and statement intonation favoured a negative interpretation, with a mean identification rate of 0.34 .

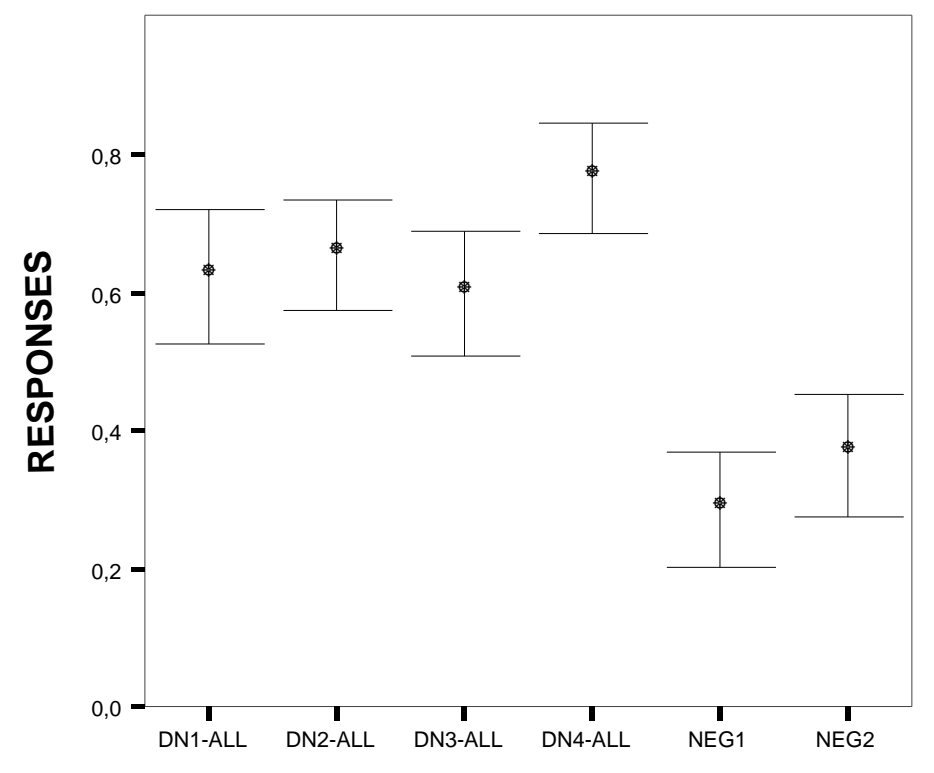

Formal Conditions

Figure 2. Mean identification rate for the interpretation of ningú 'nobody', which ranges from " 1 "=everybody to "0"=nobody, for all listeners.

Non-parametric Wilcoxon signed rank tests revealed significant differences (at $p$ $<0.001$ ) between the two groups of utterances, those conveying single negation (NEG1 and NEG2) and those conveying DN (the rest of the conditions). No significant differences were found between unmarked sentences, or between any pair of DN1, DN2, DN3 and DN4 conditions, clearly indicating that the presence of an extra n-word in the $\mathrm{Q}$ is not essential in triggering a $\mathrm{DN}$ interpretation. That is, the effect of the presence of an extra n-word in the Q does not appear to be crucial in the decisions made by the listeners, although as Figure 2 shows for each pair of target utterances (DN1ALL and DN2-ALL, DN3-ALL and DN4-ALL, and NEG1 and NEG2) the mean responses for the second member of each pair is slightly higher than for the first one. 
Yet why did the contradictory tune examples not result in an overall group mean that was closer to 1 ? If we further break down the data by speaker it is clear that while some of the listeners were very good at performing the task, others were not as sensitive to the intonation differences and did not attain a significant difference between the two groups of sentences (namely NEG1 and NEG2 on the one hand, and DN1-ALL, DN2ALL, DN3-ALL, and DN4-ALL on the other). Thus even though the subjects were provided with prior discourse contexts that were intended to activate particular assumptions, the fact that this was a non-natural experimental task which merely mimicked a real-life situation might explain why sometimes these assumptions were not actually activated. Moreover, some listeners in this artificial situation might have found themselves unable to distinguish between the two intonation contours. We think that the potential accessibility of other types of contextual and gestural information (in this specific case, a hand movement indicating visual cancellation of the speakers' assumptions) could introduce additional cues that would help to trigger the DN interpretation. $^{15}$

In sum, the results from Experiment 1 clearly show that Catalan listeners are able to use two prosodic cues to obtain a DN interpretation, namely the presence of a focalized wh- word in the question and the contradictory tune in the n-word in the answer. However, since the materials in this experiment always contained both the focalized wh- word and the contradictory contour, it did not allow us to disentangle the relative contributions of each factor in triggering a DN interpretation in Catalan Q-A pairs, nor can we say whether the presence of one of them is a sufficient condition to obtain a DN interpretation. In order to investigate the relative contribution of either focus on the wh- word or a particular intonation contour on the DN interpretation a revised set of materials were designed for Experiment 2 (see Section 3.2) which did not 
involve a one-to-one correspondence between focus on the wh- word and a marked intonation contour in the A.

\subsection{Results of Experiment 2}

The two graphs in Figure 3 show the mean identification rates for the interpretation of ningú and res ("3" =everybody/everything; "0"=nobody/nothing), as a function of the syntactic and prosodic conditions described in Section 2.3. These results again show a dual pattern of responses for the two n-words, with values under 1 for a single negation reading and values above 1.5 for DN. However, though the patterns of results are exactly the same for both n-words, the fact that we see more clearcut results for res 'nothing, everything' than for ningú 'nobody, everybody' might be due to various factors. First, as broadly noted in the linguistics literature, a well-established subjectobject asymmetry emerges here because it is easier to license a single negation and DN interpretation for object res than for subject ningú.${ }^{16}$ Second, the differences observed in Experiment 2 might also be due to a training effect, since we first conducted the test with ningú. ${ }^{17}$

Observe that the set of Q-A pairs coded as NEG1-4 and DN1-FOC and DN2FOC have been interpreted as conveying a single negation (mean rate of identification is 0.65 over 3). Crucially, those are the only six utterances in the whole set that contain a statement intonation in the A. It should also be noted that in Experiment 2 a focalized wh- word in the Q was dissociated from an n-word with a contradictory contour in the A (compare, for example, DN1-FOC — QUI no ha menjat postres? — Ningú with DN1INT -Qui no ha menjat postres? —NINGÚ), since we wanted to test our initial hypothesis that focus on the wh- question would trigger a DN interpretation in the A. On the other hand, the other six Q-A pairs display a DN interpretation, with a mean 
identification rate of 2.2 over 3 . Crucially, these cases are always pronounced with a contradictory contour in the A (see, once more, the minimal pair formed by DN1-FOC and DN1-INT).
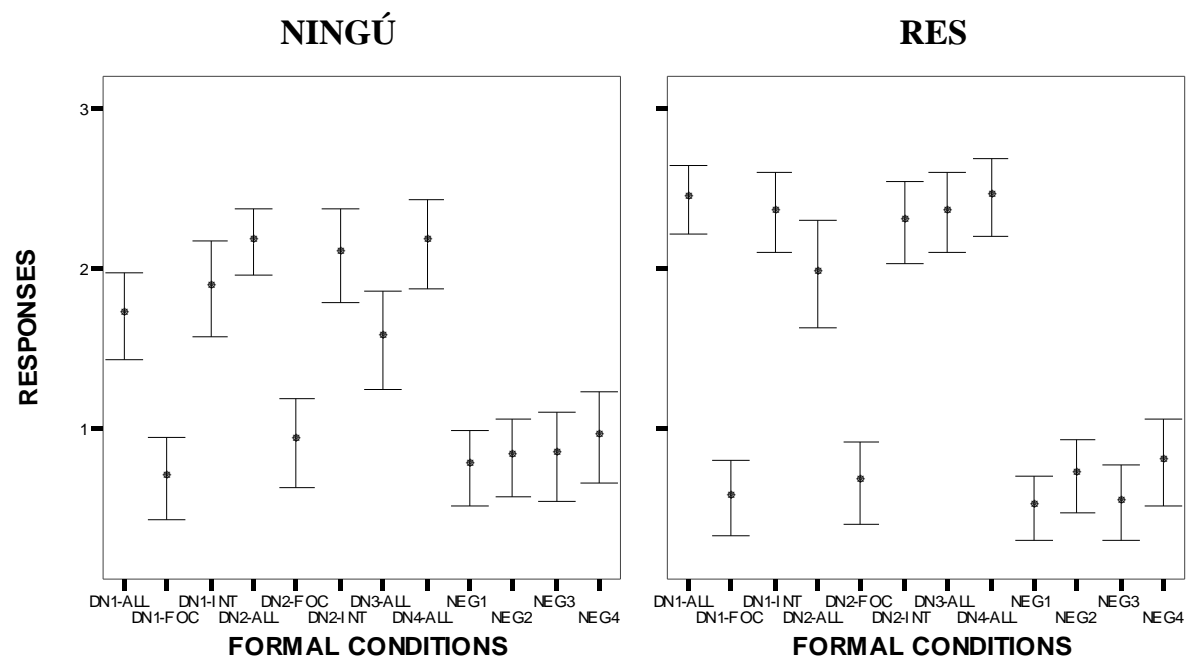

Figure 3. Mean identification rates for ningú 'nobody' (left graph) and res 'nothing' (right graph) as a function of our 12 combinations of prosodic and syntactic conditions, for all listeners. "3" =everybody/everything; " 0 "=nobody/nothing.

These results clearly demonstrate that the presence of a contradictory tune on the $\mathrm{n}$-word of the $\mathrm{A}$ is a sufficient condition to trigger a positive interpretation for the $\mathrm{n}$ word (see DN1-ALL, DN1-INT, DN2-ALL, DN2-INT, DN3-ALL, DN4-ALL). Therefore, focus alone on the wh- word is not sufficient to trigger DN in the A (see DN1-FOC and DN2-FOC), but a contradictory tune alone on the n-word of the A is (see DN1-INT and DN2-INT). No significant differences were found between any pair of DN1, DN2, DN3, and DN4 with a contradictory tune in the A (ALL and INT conditions). These results reveal that intonation, not focus, is the prime factor that conveys DN in the interpretation of Q-A dialogues. 
In sum, the results obtained with Experiments 1 and 2 reveal that intonation of the n-word is the essential cue in determining whether the n-word in the A should be interpreted as conveying single negation or DN. Therefore, this study supports the view that intonation is central to utterance interpretation.

\section{Discussion: accessing explicatures with intonation}

The results of the two experiments just described clearly show that an argumental nword (such as ningú 'nobody' or res 'nothing') that occurs in the A to a wh- negative Q in Catalan can convey either a single negation or DN interpretation depending on certain formal conditions, as well as on certain conversational conditions. But, before presenting these conditions in detail (see Sections 4.1 and 4.2), let us briefly discuss the basic concepts of a theory of pragmatics that are required in order to account for and predict DN readings in NC languages.

We start this discussion from the assumption that DN is semantically marked with respect to single negation, and it is semantically marked not only because DN is unexpected in NC languages (i.e., languages in which multiple expressions of negation give rise to a single negation reading), but also because $\mathrm{DN}$ is expressed less frequently than single negation.

From our study we conclude that $\mathrm{NC}$ languages can give rise to a $\mathrm{DN}$ reading for an isolated n-word utterance if it is pronounced with the appropriate marked intonation (i.e., in the absence of two negative operators or two strong negative quantifiers, a DN reading can be encoded by a special phonological form). This means that for a pair $<\mathrm{f}, \mathrm{m}>$, where $\mathrm{f}$ involves a marked intonational form and $\mathrm{m}$ a marked meaning, this association is more relevant (and optimal) than any other form-meaning pair $<\mathrm{f}^{\prime}, \mathrm{m}>$ and $<\mathrm{f}, \mathrm{m}^{\prime}>$, where $\mathrm{f}^{\prime}$ and $\mathrm{m}^{\prime}$ correspond to a form and meaning not optimally paired with $\mathrm{m}$ 
and $\mathrm{f}$, respectively (see above note 3 ). In our data we have no strong arguments to postulate different syntactic forms for n-words used as fragment answers. However, we do have arguments, based on an analysis of the possible intonational forms and their rates of use, to support the claim that a contradictory contour is phonologically more marked than a broad focus contour, and in this regard Horn's (1984) pattern applies nicely to our data as well. A single negation interpretation for n-words is associated with a simple rise-fall intonational form (i.e., a rise in the accented syllable followed by a low tone at the end of the utterance), and a DN interpretation is associated with a complex rise-fall-rise intonational form, thus showing the relevance of the role of intonational contours at the prosody-meaning interface.

Having assumed that $\mathrm{DN}$ is a marked meaning for isolated n-words in a $\mathrm{NC}$ language like Catalan, the next step is to explain how this reading can be achieved in the process of utterance interpretation. For this task we strongly rely on Relevance Theory (Sperber \& Wilson, 1986a/1995), an inferential pragmatic theory of communication and cognition that seeks to explain how utterances are communicated and interpreted. It is a theory that seeks to explain how hearers achieve optimal and relevant readings, a theory that distinguishes between conceptual and procedural encodings of meanings corresponding to lexical items, and a theory that aims at explaining how hearers access relevant contextual information in an ongoing discourse.

The core of the theory is that these activities follow what their proponents call the Presumption of Optimal Relevance: (i) any ostensive stimulus is relevant enough for it to be worth the addressee's effort to process it, and (ii) the ostensive stimulus is the most relevant one compatible with the communicator's abilities and preferences.

According to Sperber and Wilson, a distinction is made between conceptually encoded and procedurally encoded types of linguistic information conveyed by an 
utterance. In addition, Wilson \& Sperber (1993) argue that, although it is true that many linguistic utterances that are truth-conditional involve information about the construction of the representations to be manipulated, and many constructions which are non-truth-conditional are procedural and computational (in the sense that they involve information about how to manipulate them), it is also the case that some constructions that are truth-conditional encode procedures, and some constructions that are non-truthconditional are still representational. If we now consider the isolated n-words ningú and res given as fragment answers to our Catalan native speakers, we observe that these lexical items encode both conceptual information (denoting a human individual or a non-animate entity, and a numeral zero meaning) and procedural information (a variable quantificational meaning) on the kinds of individuals and entities that are relevant in the domain of discourse (Espinal, 2000). In doing so these items both contribute and restrict the truth-conditional content of the proposition conveyed. This means that n-words are claimed to contribute to and at the same time constrain the explicature or proposition explicitly communicated by the utterance. ${ }^{18}$ Furthermore, we claim that $n$-words with a contradictory contour constrain the explicatures because they may reverse the lexical meaning of the n-word from a negative meaning (the numeral zero) to a positive interpretation (the numeral three in our contextual settings).

In Relevance Theory it is also postulated that the explicatures conveyed by an utterance, which are constructed by enriching a linguistically encoded logical form to the point where it expresses a specific proposition, are of various sorts (Carston, 1998, 2004). That is, the postulated enrichment can also provide higher-level descriptions (i.e., the so-called higher-level explicatures; Wilson \& Sperber, 1993), such as a speechact description or a propositional attitude description. This is important because previous research carried out within this framework has already shown that intonation 
plays a central role in placing procedural constraints on the addressee's inferential task. In particular, Escandell (1998) has argued that different intonation contours associated with Spanish interrogatives encode different procedural restrictions on inferring higherlevel explicatures. Likewise, Fretheim $(1996,1998)$ has shown the role of intonation in inferential processing, in particular in facilitating the addressee's selection of the most relevant accessible context; he holds the view that "the interaction of intonation with other procedural devices of a structural or lexical sort help to select the right context and constrain the set of potential inferential computations at the hearer's end" (Fretheim, 2002). In our study we have observed that n-words with a contradictory tune introduce constraints on higher-level explicatures because this intonation contour is associated with a counterexpectational interpretation.

To sum up, intonation is conceived as a procedural device that instructs the addressee on how to enrich a linguistically encoded logical form up to the point where it is possible to infer higher-level explicatures, and on how to access the most relevant discourse-activated assumptions. Our study adds an additional hypothesis to the current debate on the interaction between intonation and relevant information at the prosody meaning interface: different intonation contours encode different constraints not only on the attitude of the speaker but also on the communicated proposition or explicature. (See Section 4.3 below.)

In addition to what we have said so far, we would like to add two more ingredients to the pragmatic model that we need in order to explain how linguistic expressions that are expected to encode single negation end up implicating DN. One of these ingredients is Sperber \& Wilson's (1986b) notion of interpretive use. Utterances can be used descriptively, to represent a description of some state of affairs by virtue of being true of that state of affairs, or they can be used interpretively, to represent a 
thought of the speaker's. "One of the assumptions a speaker intends to make manifest is that she is entertaining a thought with some particular attitude: It is on this ground that the hearer may be led to entertain a similar thought with a similar attitude" (Sperber \& Wilson, 1987:707). This means that an utterance that consists of an n-word pronounced with a broad focus intonation is an interpretation of a thought by the speaker which corresponds to the description of an actual state of affairs, while the utterance that consists of an n-word pronounced with a contradictory intonation is an interpretation of a thought by the speaker which corresponds to the interpretation of an attributed thought (i.e., a counterexpectational thought). In other words, an n-word utterance is either used descriptively to logically imply $\neg p$ (the n-word with a broad focus intonation) or it is used interpretively to contextually imply $\neg \neg p$ (the n-word with a contradictory contour).

The second ingredient we would like to mention relates to the accessibility of the relevant contextual assumptions for inferring either a single negation or DN interpretation. In our experiments we have observed a correlation between a canonical or single negation and a broad focus statement contour on the one hand, and a noncanonical intonation or DN and a contradictory intonational contour on the other. ${ }^{19}$ This correlation shows that a non-canonical form is specialized for an interpretive use and for a marked reading, and this is so because, when a contradictory contour is superimposed on the n-word, it constrains the accessibility to contextual information in such a way that the proposition denied by the n-word must be accessible (either directly or via inference) from the discourse context in which the non-canonical form occurs. In this sense we agree with those authors (Mosegaard Hansen \& Visconti, 2009; Schwenter, 2003, 2005) that claim that the proposition denied by the n-word with a marked intonation is discourse-old (Prince, 1993), and contextually activated (Dryer, 1996). 
Note that the preceding discourse contexts handled in both Experiment 1 and 2 are negative interrogative sentences and that n-words with a contradictory tune deny the proposition expressed in the preceding text. Thus, we have shown the informationstructural sensitivity of the marked intonation pattern. Under Relevance Theory assumptions a speaker selects a negative question when (s)he has some evidence of the falseness of $p$, and considers $\neg p$ to be more relevant than $p$ (Wilson \& Sperber, 1988; Espinal, 1993). In this discourse context, an n-word answer is most relevantly interpreted as implying a negative answer. However, an n-word with a contradictory contour is most relevantly interpreted as implying a denial of the accessible negative proposition warranted by the preceding text, thus implying a positive answer.

Let us now summarize the set of conditions that characterize the patterns illustrated in (1), (13), and (15).

\subsection{Formal conditions}

Syntactically, the input utterance is a marked wh- question (see Huddleston \& Pullum, 2002), since it contains the negative operator plus an optional n-word within the scope of a wh- quantifier. Formally speaking, the questions introduced in our experiments have some additional factors: either a stressed wh- word (e.g., QUI 'who', QUÈ 'what'; see DN1-ALL, DN1-FOC, DN2-ALL, DN2-FOC) or a wh- clefted structure (e.g., qui és que...lit. who is that, què és el que lit. what is the that; NEG3, NEG4, DN3-ALL, DN4-ALL). The $\mathrm{A}$ is an isolated n-word, which by default encodes a negative meaning (Espinal, 2000, 2002, 2007). This is summarized in (15).

(15) Q: wh- word + negative marker + (n-word).

A: $\quad$ n-word 
Phonologically, we have encountered two distinct relevant frames for the A. In the first frame, the n-word is pronounced in Catalan with a statement tune, as encoded in (16a); this structure corresponds to the answer given in (1a), and implies a single negation reading. The second frame consists of an n-word realized with a contradictory tune, namely the one encoded in (16b), which corresponds to the answer given in (1b) and which triggers a DN interpretation.

$$
\begin{aligned}
& \text { a. } \mathrm{L}+\mathrm{H}^{*} \mathrm{~L} \% \\
& \text { b. } \mathrm{L}+\mathrm{H}^{*} \mathrm{LM} \%
\end{aligned}
$$

In (16a) a rising pitch accent is associated with the accented syllable, and it is followed by a low boundary tone. In (16b) a rising pitch accent appears, and it is followed by a complex fall-rise boundary tone.

\subsection{Conversational conditions}

In addition to the formal conditions just summarized, some relevant conversational conditions further constrain the interpretation to be driven. We have shown that the distinction between different contours is intimately tied up with information-structural considerations.

On the one hand, when the input Q conveys a negative information question, it is assumed to be the interpretation of a desirable thought on the part of the speaker, the interpretation of a relevant negative answer (Wilson \& Sperber, 1988): for which $x, \neg p$. In this context the A (i.e., the n-words ningú or res pronounced with a broad focus statement intonation) conveys a statement, and it has a stating effect with a negative interpretation (i.e., nobody, nothing), similar to a NC sentence (e.g., Ningú no ha menjat postres 'Nobody ate dessert', No ens han enviat res 'Nothing has been sent to us'). This interpretation can be represented in the following terms: $\neg \exists x$, such that $p$, a formula that 
encodes that the final interpretation is a single negation.

On the other hand, when the input $\mathrm{Q}$ is a negative directive (or command) question (Huddleston \& Pullum, 2002), the speaker assumes that $p$ but has some evidence that $\neg p$ (on the basis of accessible contextual information). Directive (or command) questions are associated with specific syntactic and phonological formal conditions. In this context the Q is an interpretation of this counterexpectational thought on the part of the $\mathrm{S}$, a meaning which we represent as: ifor which $x, \neg p$. The A (i.e., the n-words ningú, res), pronounced with a contradictory contour, is interpreted as a denial of that discourse-activated assumption, and it has a denial effect with a DN interpretation: $\exists x$, such that $\neg \neg p$.

Observe that while in Experiment 1 an n-word with contradictory contour was associated with a negative directive (or command) question, in Experiment 2 it was dissociated from a negative command question (as illustrated in DN1-INT and DN2INT). This dissociation proves our conclusion that the intonation of the A prevails over the properties of focalized constituents in the Q.

\subsection{Discussion of the prosody-meaning interface}

So far, what we have shown is that a particular combination of formal and conversational conditions might aid the hearer at the time of interpreting utterances by enriching the input expressions in a certain direction. In particular, the experiments that we have run show that, rather than appealing to the prosodic phrasing of the $\mathrm{Q}$ or a strong stress on the wh- word occurring in the Q, the determining factor for constraining the final interpretation must be associated with the intonation contour of the A.

The presence or absence of a contradictory tune on the n-word of the A 
constrains differently the communicated proposition by conveying a single negation or DN interpretation on the one hand, and a bare statement or denial on the other. We have shown that in our experiments intonation is the primary factor that helps the hearer in the task of broadening the information codified by n-words and fleshing out a DN interpretation.

Note that these results are compatible with the common assumption in the literature on negation that the DN reading is a marked, highly constrained interpretation, which requires more effort on the part of the hearer/listener than a single negation interpretation. In the absence of any other cue, n-words can only constrain the proposition expressed through the semantic features they encode, which accounts straightforwardly for their negative meaning. However, when a salient intonation encodes procedural restrictions on the inferring of biased higher-level explicatures on the part of the speaker, then the optimal interpretation for the utterance expressed is not a single negation but rather a $\mathrm{DN}$, thus reversing the default negative meaning of $\mathrm{n}$ words. These higher-level explicatures provide information on the attitude of the speaker of the answer, the attitude that he is denying or contradicting a proposition that is part of the preceding text, or an inference warranted by the preceding text.

Finally, we would like to point out that our experimental studies support Fretheim's $(1996,1998,2002)$ and House's (1996) hypotheses on the role of intonation in inferential processing. Different intonation contours can encode different types of procedural meanings: on the one hand, they encode different constraints on higher-level explicatures (Escandell, 1998), that is, they report on the attitude of the speaker with regard to the relation between the A and the corresponding Q. But, on the other hand, we have shown that intonation contours also encode different constraints on the communicated proposition or explicature, and can reverse the zero meaning of n-words 
to a positive numeral meaning, in accordance with the available contextual setting. These results, furthermore, are pertinent to a debate which has existed within Relevance Theory since Wilson \& Sperber's (1993) seminal work (see Espinal, 1996; Fraser, 2009; de Saussure, 2009; and others) regarding the possibility that some linguistic expressions encode information that might contribute to and/or constrain various types of inferences. We have shown that intonation contours can constrain the construction of the propositional content of an utterance and that, therefore, their role is central to utterance interpretation.

\section{Conclusions}

The empirical investigation presented in this article has focused on exploring the role of a set of syntactic and prosodic factors in DN interpretation in Q-A dialogues in Catalan. With regard to syntactic conditions, we expected that either the presence of a focalized wh- operator (like QUI, qui és que, QUÈ, què és el que) or the presence of an extra nword in the Q would favour a DN interpretation for the n-word in the A. As for prosodic conditions, we expected that the presence of a focalized wh- word in the question and the presence of a contradictory intonation contour in the response would also favour a DN interpretation.

The results of both Experiments 1 and 2 have shown that Catalan listeners mainly rely on the intonation contour associated with the n-word of the A when it comes to fleshing out a full DN interpretation (see Figures 2 and 3). We have also shown that neither the presence of an overt n-word nor the presence of a focalized whword in the Q are capable of triggering DN. Rather, the presence of a contradictory tune on the n-word is what triggers a counterexpectational meaning and thus a denial of a discourse-activated assumption (namely, in our two experiments, that 'someone has not 
eaten dessert', which was activated in the prior discourse context). It is the activation of this counterexpectational meaning through intonation which is also associated with a $\mathrm{DN}$ interpretation for the n-word. It is important to stress that the variation found in the data and the fact that some speakers were not as sensitive to differences in stimuli might be due to structural factors (such as a subject-object asymmetry), or non-natural experimental conditions. It might be the case that the artificial repetition of the discourse context hindered the activation of assumptions in some speakers.

We conclude that prosody constrains meaning by guiding the hearer/listener at the time of interpreting an n-word in context. Different intonation contours encode different constraints on the communicated proposition and guide the enrichment of the linguistic content associated with an n-word that occurs as a fragment answer. Thus, in addition to the claim that prosody can help listeners interpret the assumptions and attitudes held by the speaker (or the high-level implicatures in relevance-theoretic terms), our results show that prosodic tunes can also constrain the actual interpretation (or the explicature) associated with an utterance. Furthermore, by showing that the intonation of the $\mathrm{A}$ is an important factor at the time of constraining a DN interpretation that is only underdetermined by n-words, we have reached an additional conclusion: procedural meaning is encoded not only by specific lexical items, such as quantificational expressions (wh- words, n-words, determiners), and pronouns, but intonational contours must also be investigated in this respect. 


\section{APPENDIX 1}

(i) Contextual Settings - res 'nothing'

L'encarregada d'una botiga consulta l'estat de tres productes reclamats en diverses ocasions i demana a la dependenta...

'A shopkeeper is checking the condition of three products that have been repeatedly complained about by customers and asks the shop assistant...'

(ii)Target utterances for Experiment 2 - res.

CODES

TARGET UTTERANCES

$\begin{array}{llc}\text { NEG } 1 & \text { - Res. } \\ & \text { now same, what not us have sent } & \text { nothing } \\ & \text { 'Now, what did they not send?' } & \text { 'Nothing.' } \\ \text { NEG } 2 & \text { now same, what not us have sent no provider } & \text { nothing } \\ & \text { 'Now, what did the suppliers not send?' } & \text { 'Nothing.' } \\ \text { NEG } 3 & \text { Ara mateix, què és el que no ens han enviat? } & \text { - Res. } \\ & \text { now same, what is the that no us have sent } & \text { nothing } \\ & \text { 'Now, what did they not send?' } & \text { 'Nothing.' }\end{array}$

NEG 4 - Ara mateix, què és el que no ens ha enviat cap proveïdor? - Res. now same, what is the that no us have sent no provider nothing 'Now, what did the suppliers not send?' 'Nothing.'

DN1-ALL - Ara mateix, QUÈ no ens han enviat? - RES. now same, WHAT not us have sent nothing 'Now, what did they not send?' 'Nothing.'

DN1-FOC - Ara mateix, QUE no ens han enviat? -Res. now same, WHAT not us have sent nothing 
'Now, what did they not send?'

'Nothing.'

DN1-INT

- Ara mateix, què no ens han enviat?

$-R E S$.

now same, what not us have sent

nothing

'Now, what did they not send?'

'Nothing.'

DN2-ALL - Ara mateix, QUÈ no ens ha enviat cap proveïdor? - RES.

now same, what not us have sent no provider nothing

'Now, what did the suppliers not send?'

'Nothing.'

DN2-FOC - Ara mateix, QUÈ no ens ha enviat cap proveïdor? - Res.

now same, what not us have sent no provider nothing

'Now, what did the suppliers not send?'

'Nothing.'

DN2-INT - Ara mateix, què no ens ha enviat cap proveïdor? - RES.

now same, what not us have sent no provider nothing

'Now, what did the suppliers not send?'

'Nothing.'

DN3-ALL - Ara mateix, què és el que no ens han enviat? - RES.

now same, what is the that no us have sent nothing

'Now, what did they not send?'

'Nothing.'

DN4-ALL - Ara mateix, què és el que no ens ha enviat cap proveïdor? - RES. now same, what is the that no us have sent no provider nothing 'Now, what did the suppliers not send?'

'Nothing.'

\section{Acknowledgements}

An earlier version of this study was presented at the Workshop on Procedural Meaning (October 2009, Madrid), and at the XX Colloquium on Generative Grammar (March 2010, Barcelona). We are grateful to C. Beyssade, B. Clark, V. Escandell, A.M. Falaus,

O. Fernández Soriano, T. Fretheim, B. Gili-Fivela, M.P. D’Imperio, M. Leonetti, C. de 
la Mota, P. Roseano, and D. Wilson, as well as to two reviewers of the Journal of Pragmatics for very insightful comments on some of the topics raised in this article. We would also like to thank the colleagues who participated in the perception experiments, namely: N. Argemí, M. Alemany, A. Bartra, E. Bonet, J. Borràs, T. Cabré, D. Casals, R. Craviotto, V. Crespo, F. Foguet, R. Gauchola, A. Gavarró, G. Gómez, P. Huedo, M. Llobet, J. Mascaró, M. Massanell, M. Nadeu, X. Obradors, C. Pons, Meritxell Pons, Miquel Pons, C. Queraltó, E. Ramírez, D. Recasens, J.M. Serra, J. Solà, X. Torres, I. Vallès, M.M. Vanrell, A. Víctor, and X. Villalba. Michael Kennedy-Scanlon deserves special thanks for improving the English manuscript.

This research has been funded by two research grants awarded by the Spanish Ministerio de Ciencia e Innovación, namely HUM2006-13295-C02-01FILO and HUM 2006-01758/FILO, and by two grants awarded by the Generalitat de Catalunya to both the Centre de Lingüística Teòrica (2009SGR-1073) and the Grup d'Estudis de Prosòdia (2009SGR-701). The first author also acknowledges an ICREA Acadèmia award.

\section{References}

Aguilar, Lourdes; De-la-Mota, Carme; Prieto, Pilar, (coords.) 2009. Cat_ToBI Training Materials. Web page: http://prosodia.upf.edu/cat tobi/

Blakemore, Diane, 1989. Denial and contrast: A relevance theoretic analysis of but. Linguistics and Philosophy 12, 15-37.

Carston, Robyn, 1998. Implicature, explicature and truth-theoretic semantics. In: Kempson, R. (Ed.), Mental Representations: The Interface Between Language and Reality, Cambridge University Press, Cambridge, pp. 155-181. Reprinted in Davis, S. (ed.), 1991. Pragmatics: A Reader, Oxford University Press, New York/Oxford, pp. 33-51. 
Carston, Robyn, 2004. Explicature and semantics. In: Davis, S., Gillon, B. (Eds.), Semantics: A Reader, Oxford University Press, Oxford, pp. 817-845.

Corblin, Francis, 1994. Multiple negation processing. Human Communication Research Center, Report 62, Paris.

Corblin, Francis, 1995. Compositionality and complexity in multiple negation. Logic Jnl IGPL, 3, 449-471.

Corblin, Francis, Tovena, Lucia, 2003. L'expression de la negation dans les langues romanes. In: Godard, D. (Ed.), Les Langues Romances. Problèmes de la Phrase Simple, CNRS, Pairs, pp. 281-343.

Dryer, Matthew S., 1996. Focus, pragmatic presupposition, and activated propositions. Journal of Pragmatics 26, 475-523.

Escandell, M. Victoria, 1998. Intonational and procedural encoding: the case of Spanish interrogatives. In: Rouchota, V., Jucker, A.H. (Eds.), Current Issues in Relevance Theory, John Benjamins, Amsterdam, pp. 169-203.

Espinal, M. Teresa, 1993. The interpretation of no...pas in Catalan. Journal of Pragmatics 19, 353-369.

Espinal, M. Teresa, 1996. On the semantic content of lexical items within linguistic theory. Linguistics 34, 109-131.

Espinal, M. Teresa, 2000. On the semantic status of n-words in Catalan and Spanish. Lingua, 110, 557-580.

Espinal, M. Teresa, 2002. La negació. In: Solà, J., Lloret, M.R., Mascaró, J., PérezSaldanya, M. (Eds.), Gramàtica del Català Contemporani, Empúries, Barcelona, pp. $2727-2797$.

Espinal, M. Teresa, 2007. Licensing expletive negation and negative concord in Romance languages. In: Floricick, F. (Ed.), La Négation Dans les Langues 
Romanes, John Benjamins, Lingusiticae Investigationes Supplementa 26, Amsterdam, pp. 49-74.

Falaus, Anamaria, 2006. Le paradoxe de la double négation dans une langue à concordance négative stricte. Paper presented at the Journées Romanes, Toulouse, 2-3 février 2006.

Falaus, Anamaria, 2007. Le paradoxe de la double négation dans une langue à concordance négative stricte. In: Floricick, F. (Ed.), La Négation Dans les Langues Romanes, John Benjamins, Lingusiticae Investigationes Supplementa 26, Amsterdam, pp. 75-97.

Fraser, Bruce, 2009. A critical review of the conceptual-procedural distinction. Paper presented at the conference on Procedural Meaning: Problems \& Perspectives, UNED, Madrid.

Fretheim, Thorstein, 1984. Denials and other negatives. In: Brendemoen, B., Hovdhaugen, E., Magga, O.H. (Eds.), Riepmocála: Essays in Honour of Knut Bergsland. Novus, Oslo, pp. 49-65.

Fretheim, Thorstein, 1996. Accessing contexts with intonation. In Fretheim, T., Gundel, J.K. (Eds.), Reference and Referent Accessibility, John Benjamins, Amsterdam, pp. 89-112.

Fretheim, Thorstein, 1998. Intonation and the procedural encoding of attributed thoughts: The case of Norwegian negative interrogatives. In: Rouchota, V., Jucker, A.H. (Eds.), Current Issues in Relevance Theory, Amsterdam: John Benjamins, pp. 205-236.

Fretheim, Thorstein, 2002. Intonation as a Constraint on Inferential Processing. In: Proceedings of the Speech Prosody 2002, Aix-en-Provence, France, April 11-13, 2002, pp. 307310. 
Geurts, B., 1998. The mechanism of denial. Language 74, 274-307.

Giannakidou, Anastasia, 2000. Negative ... concord? Natural Language and Linguistic Theory 18, 457-523.

Giannakidou, Anastasia, 2002. N-words and negative concord. In: Everaert M., Riemsdijk, H. van (Eds.), The Linguistics Companion, vol. III, Blackwell, Oxford, pp. 327-391.

Gunlogson, Christine, 2002. True to form: rising and falling declaratives in English. Ph.D. dissertation. UCSC.

Gussenhoven, Carlos, 2002. Phonology of intonation. State-of-the-Article. GLOT International 6, 271-284.

Haegeman, Liliane, 1995. The Syntax of Negation, Cambridge University Press, Cambridge.

Hendricks, Petra, de Hoop, Helen, Krämer, Irene, de Swart, Henriette, Zwarts, Joost, 2009. Conflicts in Interpretation, Ms. http://www.let.rug.nl/hendriks/conflict.htm Horn, Larry, 1984. Towards a new taxonomy of pragmatic inference: Q-based and Rbased implicature. In: Schffrim, D. (Ed.), Meaning, Form, and Use in Context: Linguistic Applications, GURT84. Washington: Georgetown University Press, pp. 11-42.

Horn, Larry, 1989. A Natural History of Negation. The University of Chicago Press, Chicago.

House, Jill, 2006. Constructing context with Intonation. Journal of Pragmatics 38, 15421558.

Huddleston, Rodney, Pullum, Geoffrey, 2002. The Cambridge Grammar of the English Language. Cambridge University Press, Cambridge.

Kaiser, Elsi, 2006. Negation and the left periphery in Finnish, Lingua 116, 314-350. 
Ladd, D. Robert, 1996. Intonational phonology. Cambridge University Press, Cambridge.

Laka, Itziar, 1990. Negation in Syntax: On the Nature of Functional Categories and Projections. Ph.D. Dissertation, MIT, Cambridge, Massachusetts.

Mosegaard Hansen, Maj-Britt, Visconti, Jacqueline, 2009. On the diachrony of 'reinforced' negation in French and Italian. In: Rossari, C., Ricci, C., Spiridon, A. (Eds.), Grammaticalization and Pragmtics: Facts, Approaches, Theoretical Issues, Emerald, pp, 137-171.

Pierrehumbert, Janet, 1980. The Phonetics and Phonology of English Intonation. Ph.D. Dissertation, MIT, Cambridge, Massachusetts.

Pierrehumbert, Janet, Beckman, Mary, 1988. Japanese Tone Structure. MIT Press, Cambridge, Massachusetts.

Prieto, Pilar, 2002. Entonació. In: Solà, J., Lloret, M.R., Mascaró, J., Pérez-Saldanya, M. (Eds.), Gramàtica del català contemporani. Empúries, Barcelona, pp. 393-462. Prieto, Pilar, in press. The intonational phonology of Catalan. In: Sun-Ah J. (Ed.), Prosodic Typology 2. The Phonology of Intonation and Phrasing. Oxford, Oxford University Press.

Prieto, Pilar, Aguilar, Lourdes, Mascaró, Ignasi, Torres-Tamarit, Francesc Josep, Vanrell, Maria del Mar. 2009. L'etiquetatge prosòdic Cat_ToBI. Estudios de Fonética Experimental XVIII, 287-309.

Prieto, Pilar, Rigau, Gemma, 2007. The syntax-prosody interface: Catalan interrogative sentences headed by que. Journal of Portuguese Linguistics 6.2, 29-59.

Prince, Ellen F., 1992. The ZPG letter: subjects, definiteness, and information-status. In Thompson, S., Mann, W. (Eds.), Discourse Description: Diverse Analyses of a Fundraising Text. John Benjamins, Amsterdam, pp. 295-325. 
Rizzi, Luigi, 1997. The fine structure of left periphery. In: Haegeman, L. (Ed.), Elements of Grammar, Kluwer, Dordrecht, pp. 281-337.

Rizzi, Luigi, 2001. Locality and left periphery. In: Belletti, A. (Ed.), Structures and Beyond: The Cartography of Syntactic Structures, Vol. II, Oxford University Press, Oxford, pp. 223-251.

de Saussure, Louis, 2009. On some methodological issues in the conceptual-procedural distinction. Paper presented at the conference on Procedural Meaning: Problems \& Perspectives, UNED, Madrid.

Schwenter, Scott, 2003. No and tampoco: a pragmatic distinction in Spanish negation, Journal of Pragmatics 35, 999-1030.

Schwenter, Scott, 2005. The pragmatics of negation in Brazilian Portuguese, Lingua, $115,1427-1456$.

Sperber, Dan, Wilson, Deirdre, 1986a/1995. Relevance. Communication and Cognition, Oxford: Blackwell.

Sperber, Dan, Wilson, Deirdre, 1986b. Loose talk. Proceedings of the Aristotelian Society 1985/6:153-71.

Sperber, Dan, Wilson, Deirdre, 1987. Précis of Relevance: Communication and cognition. Behavioral and Brain Sciences 10, 697-754.

De Swart, Henriette, 2010. Expression and Interpretation of Negation, Dordrecht: Springer.

de Swart, Henriette, Sag, Ivan, 2002. Negation and negative concord in Romance. Linguistics and Philosophy 25, 373-417.

Tubau, Susagna, 2008. Negative Concord in English and Romance: Syntax-Morphology Interface Conditions on the Expression of Negation. Utrecht: LOT.

Wilson, Deirdre, Sperber, Dan, 1988. Mood and the analysis of non-declarative 
sentences. In: Dancy, J., Moravcsik, J.M.E., Taylor, C.C.W. (Eds.), Human

Agency. Language, Duty and Value. Stanford University Press, Stanford, pp. 77101.

Wilson, Deirdre, Sperber, Dan, 1993. Linguistic form and relevance. Lingua 93, 1-25.

Zeijlstra, Hedde, 2004. Sentential Negation and Negative Concord. Ph.D. Dissertation, University of Amsterdam, Amsterdam.

\section{Notes}

${ }^{1}$ This term is defined by Giannakidou (2002) as in (i).

(i) $\quad N$-word: An expression $\alpha$ is an n-word iff:

a. $\quad \alpha$ can be used in structures containing sentential negation or another $\alpha$-expression yielding a reading equivalent to one logical negation; and

b. $\quad \alpha$ can provide a negative fragment answer.

${ }^{2}$ See Sperber \& Wilson (1986a/1995, 1993), Sperber \& Wilson (1987), and Carston (1998, 2004) for a description of the relevant concepts here assumed.

${ }^{3}$ On denials see, among others, Fretheim (1984) and Geurts (1998). Blakemore (1989) deals with denials from a relevance-theoretic perspective.

${ }^{4}$ As has been pointed out by Horn (1984:26), "unmarked forms tend to be used for unmarked situations and marked forms for marked situations". See also de Swart (2010) for a full description of the balance between form and meaning in the expression of negation within an optimality-theoretic approach to semantics.

${ }^{5}$ See Espinal (2007) for a description of the types of negative items in Catalan and Spanish. Examples for each type from Catalan, Spanish and French are provided in (i), where $\mathrm{NO}=$ negative operator, $\mathrm{PI}=$ polarity item and $\mathrm{NQ}=$ negative quantifier.

(i) $\mathrm{NO}=$ The negative marker no in Catalan and Spanish, Catalan discontinuous no...pas, French oral pas and written ne...pas.

PI = Gaire in Catalan, minimizers without ni both in Catalan and Spanish, the N + alguno/a structure in Spanish, quoi que ce soit in French. 
$\mathrm{NQ}=\quad$ Minimizers preceded by ni both in Catalan and Spanish, continuous no pas in Catalan.

n-words = Ningú, res, cap, gens, mai, enlloc in Catalan; nadie, ningún, nunca, nada in Spanish; personne, rien, jamais, etc. in French.

${ }^{6}$ It has been assumed that differing licensing conditions are involved in the distribution and interpretation of negative items in preverbal and postverbal positions. See Espinal (2007) for an account of the possibility of co-occurrence of the preverbal n-word with the negative operator in Catalan based on the underspecified value of a quantificational force syntactic feature, which is characteristic of $n$-words. By contrast, Zeijlstra (2004) assumes that Catalan exhibits simultaneously two different dialects: one dialect that is a Non-strict NC language and another dialect that shows Strict NC behaviour; he also makes the additional assumption that in the situation of co-occurrence of preverbal $n$-words with a negative operator the negative adverb is not semantically negative.

${ }^{7}$ The case of isolated n-words should be contrasted with that of constituents which are prosodically focused and interpreted contrastively in certain syntactic positions of the left periphery of a sentential structure. See Kaiser's (2006) study on the interaction of negation and fronted contrastive constituents in Finnish. See also Prieto \& Rigau (2007) for an analysis of Catalan interrogative sentences headed by que 'that' which has been developed within Rizzi’s hypothesis for the left periphery.

${ }^{8}$ By the term 'contradictory intonation contour' we refer to a statement of the obvious contour (Aguilar et al. 2009) used to deny a discourse-accessible proposition.

${ }^{9}$ The reader can access the website of the Cat_ToBI Training Materials (Aguilar et al., 2009), which contains sound examples with labelled utterances and labelling exercises. It is intended to be a practical tool for learning how to label prosodically diverse Catalan speech data.

${ }^{10}$ As one of our reviewers has pointed out, the labels NEG1 and NEG2 used in Experiment 1 and NEG3 (later included in Experiment 2) have been used in the literature on non-canonical negatives to describe a rather different set of structures, namely strictly preverbal negation (NEG1), a preverbal negative expression repeated sentence-finally typically without a preceding pause (NEG2), and a sentence-final negation in the absence of any preverbal negative (NEG3) (see Schwenter's 2005 analysis of negation in Brazilian Portuguese, among others). Please note that in this paper we make use of these same labels but with a different meaning intended.

${ }^{11}$ The codes for the recorded stimuli used Experiment 1 are as follows: 
Code Description of the target utterances

NEG1 Information-seeking wh- question (focus on object NP) and broad focus intonation contour on ningú 'nobody'.

NEG2 Focused wh- question (focus on qui és que) with an extra n-word, and broad focus intonation contour on ningú 'nobody'.

DN1-ALL Focused wh- question (focus on the wh- word qui) and contradictory contour on ningú.

DN2-ALL Focused wh- question (focus on the wh- word qui) with an extra n-word, and contradictory contour on ningú.

DN3-ALL Focused wh- question (focus on qui és que) and contradictory contour on ningú.

DN4-ALL Focused wh- question (focus on qui és que) with an extra n-word and contradictory contour on ningú.

${ }^{12}$ A reviewer has pointed out the possibility that the presence of a wh- word might not be a necessary condition. In fact, a negative question such as ¿Ningú no ha menjat postres? lit. nobody not has eaten dessert 'Didn't anybody eat dessert?' can admit a yes/no answer, as well as an isolated ningú, with either a broad focus intonation contour (implying single negation) or a contradictory contour (implying DN). However, we did not test this structure in our experiments.

${ }^{13}$ We chose these two Catalan n-words in our experiments for two reasons: we wanted to test n-words that occur in subject and object argument positions (thus, excluding adjunct n-words, e.g., mai 'never/ever'), and n-words that occur as head Nouns (thus excluding n-words that are Determiners, e.g., cap 'no/any').

${ }^{14}$ The codes for the recorded stimuli used Experiment 2 are as follows:

Code Description of the target utterances

NEG1 Information-seeking wh- question (focus on object NP) and broad focus intonation on ningú 'nobody'.

NEG2 Focused wh- question (focus on qui) with an extra n-word and broad focus intonation on ningú 'nobody'.

NEG3 Focused wh- question (focus on qui és que) and broad focus intonation on ningú 'nobody'. 
NEG4 Focused wh- question (focus on qui és que) with an extra n-word and broad focus intonation on ningú 'nobody'.

DN1-ALL Focused wh- question (focus on the wh- word qui) and contradictory contour on ningú.

DN1-FOC Focused wh- question (focus on the wh- word qui) and broad focus intonation on ningú.

DN1-INT Information-seeking wh- question (focus on object NP) and contradictory contour on ningú.

DN2-ALL Focused wh- question (focus on the wh- word qui) with an extra n-word and contradictory contour on ningú.

DN2-FOC Focused wh- question (focus on the wh- word qui) with an extra n-word and broad focus intonation on ningú.

DN2-INT Information-seeking wh- question (focus on object NP) with an extra n-word and contradictory contour on ningú.

DN3-ALL Focused wh- question (focus on qui és que) and contradictory contour on ningú.

DN4-ALL Focused wh- question (focus on qui és que) with an extra n-word and contradictory contour on ningú.

${ }^{15}$ We suspect that gestural information as well as face expression are most probably additional factors that help the hearer/listener in understanding utterances. However, we did not test the role of these elements in our experiments.

${ }^{16}$ A subject - object asymmetry has already been described in relation to different phenomena (e.g., in wh- question formation and comprehension, in the processing of relative clauses, in the acquisition of DPs by children, etc.).

${ }^{17}$ One of the reviewers suggests that the differences in the results obtained for ningú and res might be due to differences in the context interpretation for these distinct negative words, in the sense that the target contextual settings would favour a bias for non-human referents. However, we think that this cannot be the case. On the one hand, the contextual settings for Experiment 2 did not induce any preference for one of the two readings. On the other hand, the discourse contexts set in the target utterances for Experiment 2-ningú and for Experiment 2-res showed exactly the same combinations of (focalized and non- 
focalized) wh- expressions, the negative adverb no, and an optional n-word (res 'nothing/anything' in the case of the ningú subexperiment, and cap 'no/any' in the case of the res subexperiment).

${ }^{18}$ The issue that lexical items can encode both conceptual and procedural information and that it is not always the case that there is a sharp distinction between contributions to and constraints on the interpretation is discussed in Espinal (1996). In that paper it is argued that (i) there are lexical items whose conceptual encoding is inextricably associated with procedural encoding (e.g., the strong pronoun ell 'he' in Catalan); (ii) there are lexical items that contribute both to the proposition expressed and to higher-level explicatures (e.g., mood indicators= and attitudinal particles); and (iii) there are lexical items that contribute both to the proposition expressed and to implicatures (e.g., Catalan no...pas; Espinal 1993).

${ }^{19}$ In relevance-theoretic terms, and following previous work by Espinal (1993) on Catalan and Schwenter (2003) on Spanish, we assume that the distinction between canonical negation (expressed by Catalan and Spanish no) and non-canonical negation (expressed by Catalan no...pas, and Spanish tampoco) is that non-canonical forms are specialized for an interpretive use and imply some sort of marked reading. Additional premises are required in the assumption schema in order to understand why the speaker's choice is a marked form of negation. Thus, for example, the use of no...pas is relevant only when certain contextual propositions may be drawn: the hearer of a no...pas utterance interprets it as either cancelling a contextual assumption or confirming someone's expectations. 